\title{
Evaluating Reflected GPS Signal as a Potential Tool for Cotton Irrigation Scheduling
}

\author{
Xin Qiao"1, Ahmad Khalilian ${ }^{*}$, Jose 0. Payero², Joe Mari Maja ${ }^{2}$, Charles V. Privette1, \\ Young J. Han ${ }^{1}$ \\ ${ }^{1}$ Department of Agricultural and Environmental Sciences, Clemson University, Clemson, SC, USA \\ ${ }^{2}$ Edisto REC, Clemson University, Blackville, SC, USA \\ Email:xqiao@clemson.edu, *akhlln@clemson.edu,jpayero@clemson.edu,jmaja@clemson.edu, \\ privett@clemson.edu,yhan@clemson.edu
}

Received 6 June 2016; accepted 17 July 2016; published 20 July 2016

Copyright (C) 2016 by authors and Scientific Research Publishing Inc. This work is licensed under the Creative Commons Attribution International License (CC BY). http://creativecommons.org/licenses/by/4.0/

(c) $\underset{\mathrm{EY}}{\mathrm{B}}$ Open Access

\section{Abstract}

Accurate soil moisture content measurements are vital to precision irrigation management. Remote sensing using the microwave spectrum (such as GPS signals) has been used for measuring large area soil moisture contents. In our previous work, we estimated surface soil moisture contents for bare soil using a GPS Delay Mapping Receiver (DMR) developed by NASA. However, the effect of vegetation was not considered in these studies. Hence the objectives of this study were to: 1) investigate the feasibility of using DMR to determine soil moisture content in cotton production fields; 2) evaluate the attenuation effect of vegetation (cotton) on reflected GPS signal. Field experiments were conducted during the 2013 and 2014 growing seasons in South Carolina. GPS antennas were mounted at three heights $(1.6,2.7$, and $4.2 \mathrm{~m})$ over cotton fields to measure reflected GPS signals (DMR readings). DMR readings, soil core samples, and plant measurements were collected about once a week and attenuation effect of plant canopy was calculated. Results showed that DMR was able to detect soil moisture changes within one week after precipitation events that were larger than $25 \mathrm{~mm}$ per day. However, the DMR readings were poorly correlated with soil volumetric water content during dry periods. Attenuation effect of plant canopy was not significant. For irrigation purpose, the results suggested that the sensitivity of reflected GPS signals to soil moisture changes needed to be further studied before this technology could be utilized for irrigation scheduling in cotton production. Refinement of this technology will expand the use of advanced remote sensing technology for site-specific and timely irrigation scheduling. This would eliminate the need to install moisture sensors in production fields, which can interfere with farming operations and increase production costs.

\footnotetext{
*Corresponding author.
} 
Keywords

\section{Remote Sensing, GPS, Soil Volumetric Water Content, Cotton, Irrigation}

\section{Introduction}

Competition for limited water resources is one of the most critical issues currently affecting civilization. The ability to make more water available for domestic, agricultural, industrial and environmental uses will depend on better management of water resources, watersheds, and storm water runoff. Accurate soil moisture measurements are vital for improving agricultural management practices. The large contrast between the dielectric constants of water $(\varepsilon w \approx 80)$ and dry soil $(\varepsilon s \approx 3-5)$ at microwave frequencies has provided an opportunity to estimate soil moisture contents using microwave signals [1]. The relative dielectric constant of soil medium $(\varepsilon)$ is usually a complex number and given as:

$$
\varepsilon=\varepsilon^{\prime}+j \varepsilon^{\prime \prime}
$$

where $\varepsilon^{\prime}$ is permittivity of soil medium, $\varepsilon^{\prime \prime}$ is the loss factor, and $j$ is the imaginary unit $\sqrt{-1}$. "Electromagnetically, a soil medium is, in general, a four-component dielectric mixture consisting of air, bulk soil, bound water, and free water" [2]. Various models have been used to establish the relationship between the complex dielectric constant of a soil-water mixture and soil volumetric water content $(\theta)$ [2]-[4]. Model developed by [3] predicts the dielectric constant of soil over a soil moisture range between 0 and $0.5 \mathrm{~cm}^{3} \cdot \mathrm{cm}^{-3}$ for different soil textures at two frequencies of 1.4 and $5 \mathrm{GHz}$. The other model developed by [4] is a semi-empirical model, which utilizes soil volumetric water content and soil texture as inputs and predicts the dielectric constant of soil for various soil textures at wider range of microwave frequencies (1.4 to $18 \mathrm{GHz}$ ).

Soil moisture can be estimated from microwave frequencies using active or passive remote sensing. The active remote sensing technique utilizes radar, which transmits electromagnetic waves to the ground surface and measures the backscattered signals. The passive remote sensing on the other hand, utilizes a radiometer, which measures thermal microwave emission from the soil surface [5]. However, the microwave radiometer requires complex calibration and a large antenna to achieve high surface spatial resolution [6]. Active remote sensing is further divided into monostatic or bi-static radar, depending on whether transmitting and receiving antennas are co-located. The backscattered signal measured by the active system and the thermal microwave emission measured by the passive system both depend on the dielectric constant of soil and thus are affected by soil volumetric water content. Active remote sensing has higher spatial resolution and is more sensitive to surface roughness and vegetation cover, compared to passive remote sensing [1]. The limitations of both active and passive remote sensing are minimized in the NASA's Soil Moisture Active Passive (SMAP) mission by combining these two methods using a radar and a radiometer [7].

Various active or passive systems are currently mounted on ground carriers, aircrafts, or spacecrafts for the purpose of soil moisture monitoring with different spatial resolutions. Over ground level, [8] mounted a radiometer operating at $1.4 \mathrm{GHz}$ on a tower and compared radiometer readings with time-domain reflectometer (TDR) soil moisture readings at different growth stages of clover grass. An aircraft-mounted electronically scanned thinned array radiometer (ESTAR) was used to map soil moisture over the Little Washita watershed in Oklahoma [9]. While the Soil Moisture and Ocean Salinity (SMOS) mission [10] and recently launched SMAP satellites [7] provide soil moisture data on a global scale.

Recently, utilization of GPS signal for remote sensing of soil moisture has been demonstrated over various systems. Geophysical and geodetic intended GPS receivers were utilized for soil moisture retrieval with resolution of $300 \mathrm{~m}^{2}$ [11]. In 2002, the National Aeronautics and Space Administration (NASA) developed a GPSbased sensor technology that operates by recording the GPS signal reflected from the surface of Earth [12] [13]. Such a system (modified GPS Delay Mapping Receiver-DMR), which utilizes L1 GPS signal, was mounted on an aircraft [12] [13] and tractor-mounted boom [14] for soil moisture measurement. The DMR system is compact in size and only uses low-gain antenna, giving advantages compared to radiometers and other remote sensing instruments [15]. In our previous work [14] [16], we estimated surface soil moisture contents for bare soils using a DMR. However, the effect of broad leaf vegetation (such as cotton) was not considered in these studies. 
Therefore, the objectives of this study were to: 1) investigate the feasibility of using a DMR to determine soil moisture content in a cotton field; and 2) evaluate the attenuation effect of vegetation (cotton) on reflected GPS signal. This information has potential application for site-specific irrigation management.

\section{Methodology}

\subsection{Site Condition}

Field experiments were conducted at the Edisto Research and Education Center (EREC) of Clemson University near Blackville, South Carolina (Latitude 33 21'55.34N, Longitude 81 $19^{\prime} 48.22^{\prime \prime} \mathrm{W}$ ), during the 2013 and 2014 cotton growing seasons. In 2013, the experiment was conducted in a cotton field equipped with a lateral variable rate irrigation system (Lateral Field, LF). In 2014, in addition to LF field, a separate field equipped with drip irrigation system was used (Drip Field, DF). Field LF was planted with cotton variety DP 1050 on May 22, 2013 and May 7, 2014. The DF field was planted to cotton variety PHY333WRF on May 27, 2014. During both years, plant density was 82,145 seeds per hectare with 96-cm row spacing. The DF field allowed testing the effect of different levels of vegetation on GPS reflectivity since cotton at this field was planted at a later date. The plot size at both fields was $7.6 \mathrm{~m}$ by $15.2 \mathrm{~m}$. Both fields had the same soil type, Varina loamy sand (Fine, kaolinitic, thermic Plinthic Paleudults).

\subsection{Field Instrumentation}

The DMR is a bi-static system, which uses two antennas with a zenith Right Hand Circularly Polarized (RHCP) antenna (3G15A-XS-1, Antcom, U.S.A.) viewing the sky and a nadir Left Hand Circularly Polarized (LHCP) antenna (3G15L-A-XS-1, Antcom, U.S.A.) viewing the ground. The DMR system utilizes a Zarlink GP2010/ 2021 chipset (ZarlinkSemiconductors, Ottawa, Canada) which has two antenna inputs and, therefore, both the direct and reflected signals can be acquired.

In 2013, the antenna platform (including RHCP and LHCP GPS antennas) was mounted on the lateral VRI at the LF field (Figure 1). The platform was made of two layers of plastic board with one layer of aluminum sheet in between. In 2014, the platform was mounted on a high-boy sprayer (Figure 1) to allow reflectivity readings to be collected from the two fields at different heights. The DMR was connected to the two antennas through two separate coaxial cables. A GPS inline amplifier (LA-21-1575-100-S, Raven Industry) was used before connecting the coaxial cable to each antenna. The DMR was located inside the lateral VRI system control box in 2013 and inside the high-boy sprayer cab in 2014.

\subsection{System Calibration and Resolution}

The DMR records the signal strength of direct and reflected GPS signal from the RHCP and LHCP antennas, respectively. The instrument output, which is the ratio of strength of reflected signal to direct signal, can be used to estimate surface reflectivity. Hence, it is important to make sure the output difference of the two DMR channels is only due to ambient environment, rather than the circuitry noise. The two input channels inside the DMR were evaluated using a balanced RF power divider, as explained by Privette et al. [16], and the signal-to-noise

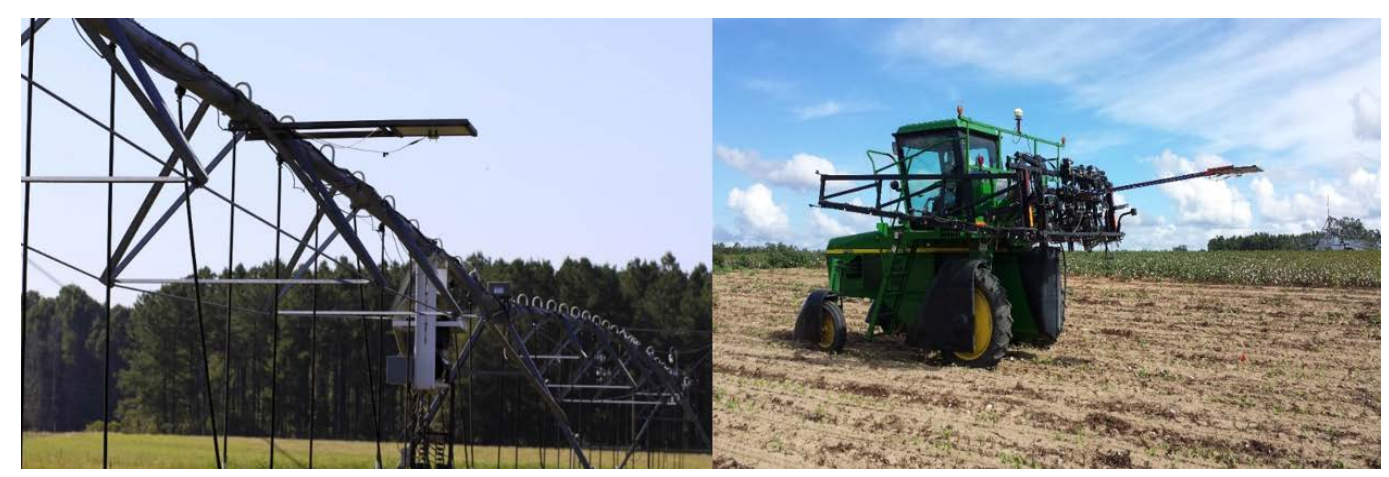

Figure 1. GPS antennas mounted on lateral VRI (left) and on a high-boy sprayer (right) during 2013 and 2014, respectively. 
ratio (SNR) of each channel was recorded. In 2014, the system was also calibrated over a surface with known reflectivity, which was a circular plastic container ( $2.4 \mathrm{~m}$ diameter and $0.3 \mathrm{~m}$ deep) filled with water. The reflectivity of a water body is relatively constant $\left(\Gamma_{s}=0.61\right)$ at a temperature range from $20^{\circ} \mathrm{C}$ to $30^{\circ} \mathrm{C}$ and GPS satellite elevation angles between 50 and 90 degrees [13] [15]. The calibration factor $\left(f_{c}\right)$, was calculated as described by [15]:

$$
f_{c}=\frac{\Gamma_{s}}{G_{c}}
$$

where $G_{c}$ is reflectivity from DMR. This calibration factor accounts for noises such as variation in satellite power, instrument temperature, cables, and cable connectors [15]. It should be pointed out that this scale factor was unique for each satellite and day of data acquisition.

Before taking appropriate soil and plant samples in the field, it was necessary to calculate the resolution of the DMR signal. This resolution was calculated using equation 3 [13], assuming that the GPS reflection was specular, and that the reflectivity came from the First Fresnel Zone.

$$
A=\pi \times \frac{\sqrt{h \lambda \sin \gamma}}{(\sin \gamma)^{2}} \times \frac{\sqrt{h \lambda \sin \gamma}}{\sin \gamma}
$$

where $A$ is area $\left(\mathrm{m}^{2}\right)$ of First Fresnel Zone, $h$ is height (m) of nadir antenna (LHCP antenna) above surface, $\gamma$ is the elevation angle (degree) of satellite signal.

\subsection{Data Collection}

The satellites traverse an arc in the sky; therefore, during a data acquisition event, the apparent reflection point must then describe an arc on the ground. Since the repeat time for the satellites and their illumination is approximately twice per day (exactly twice per sidereal day), arc paths can be constructed based on the location of the GPS reflectometer [14]. Using this method, the GPS receiver (DMR) was located in each plot in a way that the reflected arc paths would cross over predetermined locations inside the plots (Figure 2).

In both years, data was collected about once a week, during cotton growing season. In 2013, the antenna platform was moved to a predetermined sampling location (reference point) in each experimental plot and the DMR data was collected for 20 minutes. Soil core samples and plant measurements were also collected from the predicted satellite reflection paths. Soil samples were taken at 10 and $20 \mathrm{~cm}$ depths and were analyzed for volumetric water content (VWC). Plant parameters such as leaf water potential and stomatal conductance were measured using Model 600 Pressure Chamber (PMS Instrument Company, USA) and SC-1 Leaf Porometer (Decagon Inc., USA), respectively. Similar procedure were followed in 2014, however, the DMR data was collected for 10 minutes per plot, and soil samples were taken from three depths $(5,10$, and $15 \mathrm{~cm})$. In addition, two randomly selected plant samples were taken and dried in oven at $65^{\circ} \mathrm{C}$ for 72 hours to obtain plant gravimetric moisture content (wet-basis), which was calculated as [17]:

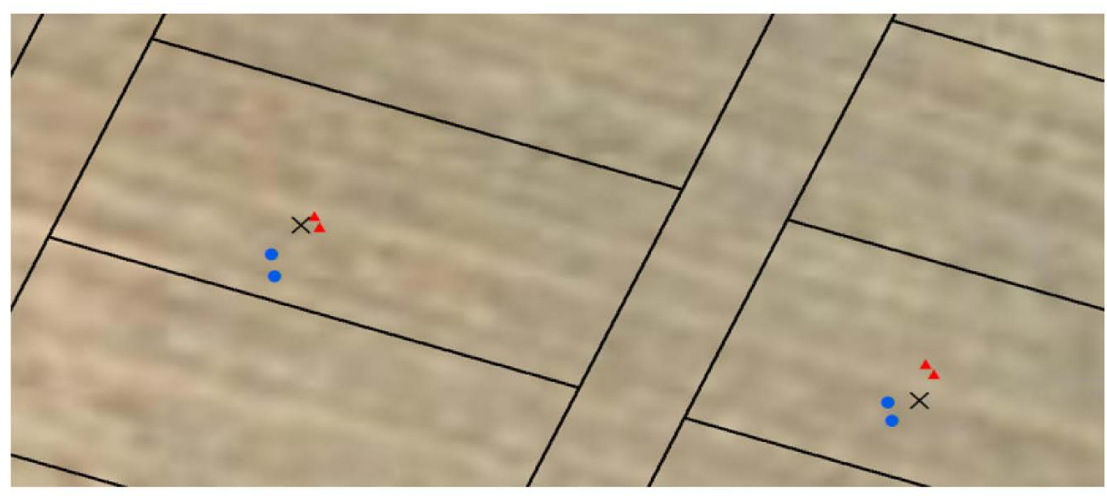

- Are points on 2013/09/04 Are points on 2013/09/09 $\times$ DMR positions $\square$ Plot Plan

Figure 2. An example of predicted reflected GPS arc path with respect to locations of antenna platform. 


$$
M C_{W}=\left[\frac{G_{W}-G_{D}}{G_{W}}\right]
$$

where $G_{W}$ is mass of wet material and $G_{D}$ is mass of dry material. Attenuation of GPS signal caused by plants was calculated as [18]:

$$
L_{a}^{\prime}(\theta)=\exp \left[\frac{4 \pi}{3 \lambda_{0}} V_{l} \varepsilon_{l}^{\prime \prime} h_{l} \sec (\theta)\right]
$$

where $L_{a}^{\prime}(\theta)$ is leaf loss factor due to canopy cover, $V_{l}$ is biomass volume moisture content and is dimensionless, $h_{l}$ is canopy height (m), $\varepsilon_{l}^{\prime \prime}$ is loss component of the dielectric constant of water containing leaves (dimensionless), $\lambda$ is wavelength (m), $\theta$ is incidence angle and equal to $\left(90^{\circ}-\gamma\right)$.

The dielectric constant of plant $\left(\varepsilon_{l}\right)$ was calculated according to [19]. The reflectivity was then adjusted by the leaf loss factor due to canopy cover (Equation (5)) and calibration factor over water (Equation (2)):

$$
G_{c_{\_} \text {adjusted }}=G_{c} \times f_{c} / L_{a}^{\prime}
$$

For each successful data acquisition event in each plot, the DMR stored a series of txt files, including: DCOERR.txt (delay timing information), DEBUG.txt, DELYSUM.txt, DELYTIC.txt (reflected signal strength), DIRECT.txt (direct signal strength), NAVSTATE.txt (DMR position), RINEX2N.txt, and RINEX2O.txt. Satellite information was stored in the two RINEX files. Data was stored at every 0.1 second, named "tics". For each series of txt file obtained at each plot, a Matlab program developed by NASA was used to calculate average reflectivity during the sampling cycle (20 min in 2013 and $10 \mathrm{~min}$ in 2014). Linear regression was used to determine the correlation of reflectivity, either adjusted (in 2014) or not adjusted (in 2013), with volumetric water content of soil and crop stress parameters (stomatal conductance and leaf water potential).

\section{Results}

\subsection{System Resolution and Calibration}

The resolution of the DMR system changes with satellite elevation angle and antenna height (Equation (3)). The DMR software is set to accept only high elevation angle satellites (greater than 60 degrees) to make the area of reflection specific to the area directly below the receiver [13]. Therefore, the resolution of the DMR was calculated for elevation angles from 50 to 90 degrees. During 2013, when antennas (RHCP and LHCP) were mounted on the VRI at height of $4.16 \mathrm{~m}$, the resolution of DMR ranged from 4.24 to $2.49 \mathrm{~m}^{2}$, for satellite elevation angles of 50 to 90 degrees. During 2014, the antennas were mounted on the back of a high-boy sprayer and the height of antennas could change from 1.6 to $2.7 \mathrm{~m}$. At height of $2.7 \mathrm{~m}$, the resolution ranged from 2.75 to $1.61 \mathrm{~m}^{2}$, for elevation angles of 50 to 90 degrees, while at height of $1.6 \mathrm{~m}$, the resolution ranged from 1.97 to $0.55 \mathrm{~m}^{2}$. The resolutions of DMR with elevation angle under different heights are shown in Figure 3. The plot size for both experimental fields (LF and DF) was large enough to exceed the DMR resolution.

During 2014, the DMR was calibrated over a circular water body on different dates for different satellites. The calibration factor $\left(f_{c}\right)$ ranged from 1.03 to 1.21 with standard deviation of 0.06 . The daily average calibration factor was used to scale reflectivity collected on the corresponding date. It was reported by [13] that DMR calibration factors ranged from 1.65 to 1.98 for data collected from an aircraft. The difference in calibration factor between the two studies might be due to differences in elevation of data collection. In addition, the top and bottom channels of the DMR system had similar signal to noise ratio (SNR) and there was a very strong correlation in SNR between the two channels.

\subsection{Reflectivity and Soil Water Contents}

Figure 4 shows relationship between reflectivity measurements and soil VWC, collected at 10 and $20 \mathrm{~cm}$, during 2013. The reflectivity data for 2013 was not adjusted by calibration factor or loss factor due to leaves. Reflectivity significantly correlated with VWC with linear relationship at $10 \mathrm{~cm}$ and $20 \mathrm{~cm}$ with $\mathrm{R}^{2}$ equal to $0.34(\mathrm{P}=$ $0.0004)$ and 0.18 ( $\mathrm{P}=0.0149)$, respectively. As stated in [1], microwave signals, including GPS signal, can only accurately measure soil moisture of a thin layer of soil on the order of $5 \mathrm{~cm}$. It is possible that the lower $\mathrm{R}^{2}$ at 20 $\mathrm{cm}$ depth could be due to limitation of GPS signal penetration depth. It was noticed that, when VWC was low, 


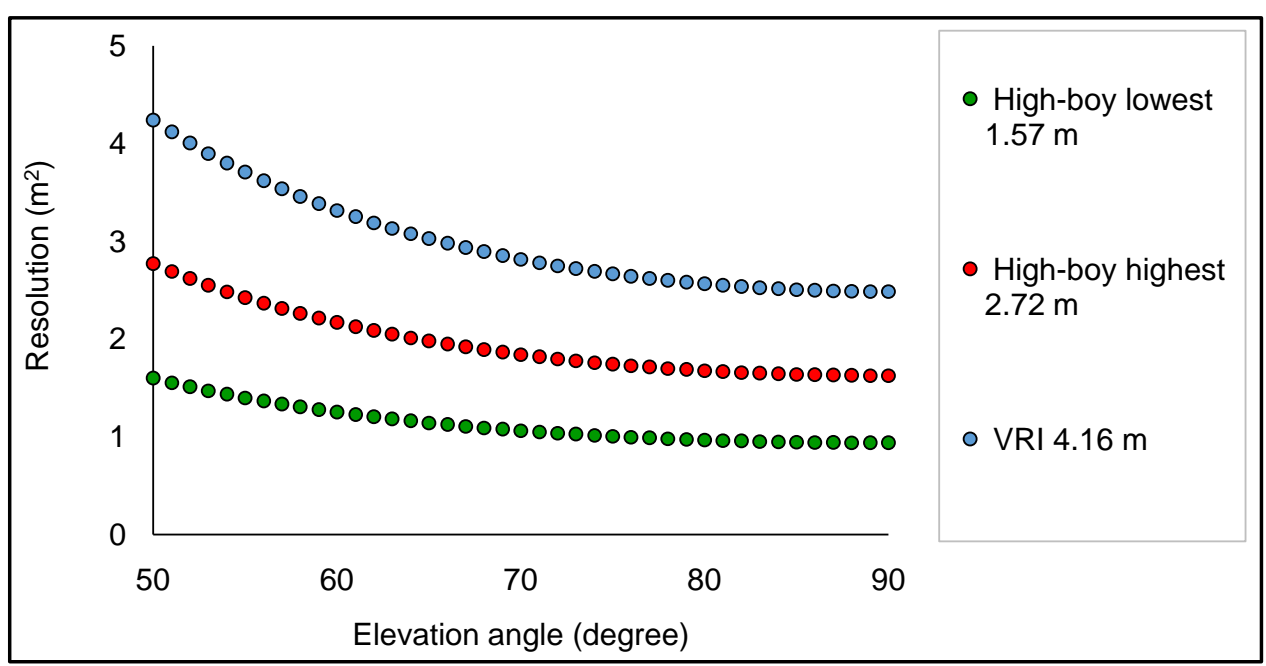

Figure 3. Resolution of DMR with elevation angle for antennas mounted at 1.57, 2.72, and $4.16 \mathrm{~m}$.
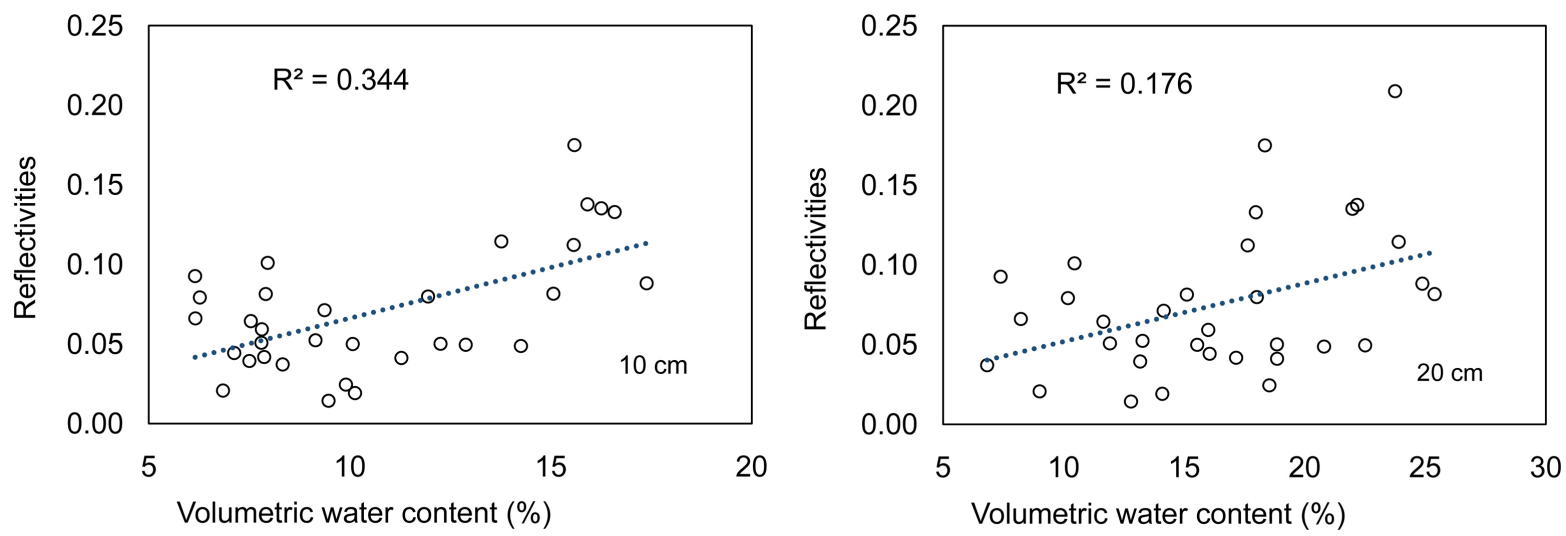

Figure 4. Correlations of reflectivity with volumetric water content of soil at 10 (left) $\mathrm{cm}$ and $20 \mathrm{~cm}$ (right) depths during 2013.

the DMR was not able to detect changes in soil moisture (Figure 4). To further investigate this, data collected within one week following large rainfall events (daily rainfall exceeding $25.4 \mathrm{~mm}$ ) were separated from other data points. For example, on Aug 20th, 2013, there was $26.5 \mathrm{~mm}$ of rainfall, and data sampled on $21^{\text {st }}, 22^{\text {nd }}, 26^{\text {th }}$, and $27^{\text {th }}$ in August of 2013 were referred as “After Precipitation" points. Other data points were referred as "Dry" points. Figure 5 shows correlation of reflectivity to VWC after data was separated. Correlation of reflectivity with VWC was improved for measurements taken at $10 \mathrm{~cm}$. However this was not true for VWC collected at 20 $\mathrm{cm}$. Similarly, reflectivity was not significantly correlated with leaf water potential or stomatal conductance, as indicated by low $\mathrm{R}^{2}$ of 0.04 and $0.02(\mathrm{P}=0.107$ and $\mathrm{P}=0.246)$, respectively.

During 2014, reflectivity measurements were adjusted by average calibration factors obtained on different dates. For antenna height of $1.6 \mathrm{~m}$, reflectivity correlated with VWC collected at 5 , 10 , and $15 \mathrm{~cm}$ with $\mathrm{R}^{2}$ of $0.30(\mathrm{P}=0.0015), 0.24(\mathrm{P}=0.0053)$, and $0.27(\mathrm{P}=0.0031)$, respectively. For antenna height of $2.7 \mathrm{~m}$, reflectivity correlated with VWC at 5,10 , and $15 \mathrm{~cm}$ with $\mathrm{R}^{2}$ of $0.17(\mathrm{P}=0.0236), 0.08(\mathrm{P}=0.129)$, and $0.17(\mathrm{P}=$ 0.0226), respectively.

During the period of data sampling in 2014, there was heavy rainfall on Sep $9^{\text {th }}(27.4 \mathrm{~mm})$, Sep $17^{\text {th }}(36.9$ $\mathrm{mm})$, and Sep $21^{\text {st }}(21.4 \mathrm{~mm})$. Data collected between Sep $9^{\text {th }}$ and Sep $26^{\text {th }}$ was separated as "After Precipitation" points. Similar to 2013, correlation of reflectivity with VWC improved after separating data points in two groups (Figure 6). For antenna height of $1.6 \mathrm{~m}$, reflectivity correlated with VWC collected at 5, 10, and $15 \mathrm{~cm}$ with $\mathrm{R}^{2}$ of $0.54(\mathrm{P}=0.0097), 0.42(\mathrm{P}=0.0303)$, and $0.45(\mathrm{P}=0.0233)$, respectively. For antenna height of 2.17 $\mathrm{m}$, reflectivity correlated with VWC collected at 5,10 , and $15 \mathrm{~cm}$ with $\mathrm{R}^{2}$ of $0.68(\mathrm{P}=0.0035), 0.15(\mathrm{P}=$ 

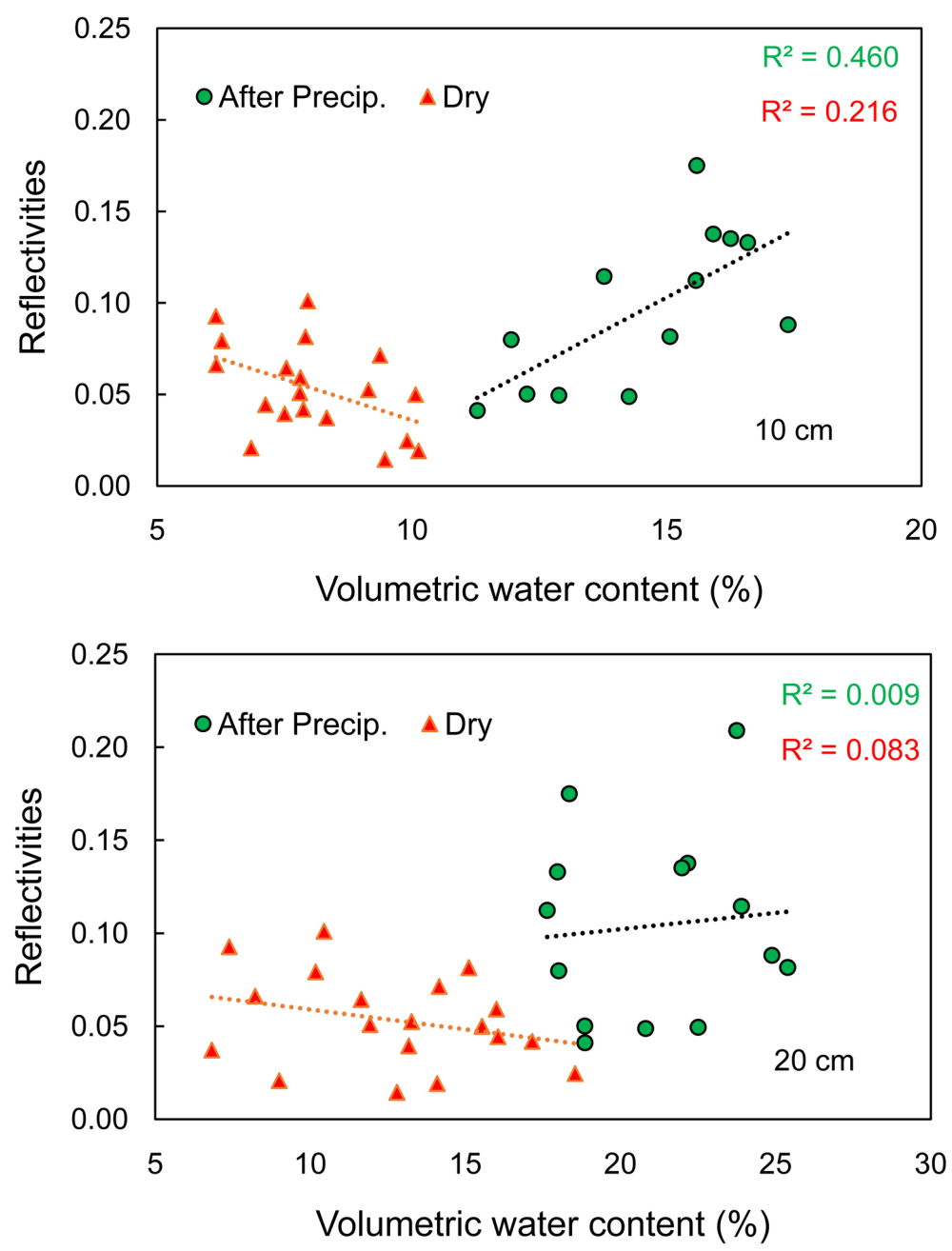

Figure 5. Correlations of reflectivity with volumetric water content of soil at 10 (left) $\mathrm{cm}$ and $20 \mathrm{~cm}$ (right) depths after data was separated during 2013.

0.0266), and 0.45 ( $P=0.0335)$, respectively. Similar to 2013, reflectivity was less correlated with VWC collected during “Dry” periods (Figure 6). The increase in $\mathrm{R}^{2}$ values for wetter soils agrees with previous finding by [15] who concluded that at least some precipitation was required in order to use reflected GPS signal to measure soil moisture. Similarly, [13] found that DMR was able to detect soil moisture changes within 12 hours of rainfall.

\subsection{Attenuation Effects of Vegetation}

The measured gravimetric moisturecontent of cotton plant $\left(\mathrm{MC}_{\mathrm{W}}\right)$ was in the range of 0.6 to 0.85 . According to [19], dielectric constant of vegetation was modeled as three components: a nondispersive residual component, a free-water component, and a bulk vegetation-bound water component. When gravimetric moisture content of cotton increased, volume fraction of free water and bulk vegetation-bound water increased also. As a result, both real $\left(\varepsilon^{\prime}\right)$ and imaginary components $\left(\varepsilon^{\prime \prime}\right)$ of dielectric constant $(\varepsilon)$ of cotton plant were increased with $\mathrm{MC}_{\mathrm{W}}$ (Figure 7). The imaginary components $\left(\varepsilon^{\prime \prime}\right)$ of Dielectric constant was used to caculate the loss factor due to cotton leaves. Figure $\mathbf{8}$ shows leaf loss factor increased as volumetric moisturecontent of cotton leaves increased.

The effect of attenuation to GPS reflectivity caused by cotton canopy was accounted for by multiplying the original reflectivity by the loss factor due to leaves. It should be pointed out that the attenuation of GPS signal due to cotton stalks would be insignificant in this study, since only satellites at high elevation angles were selected 

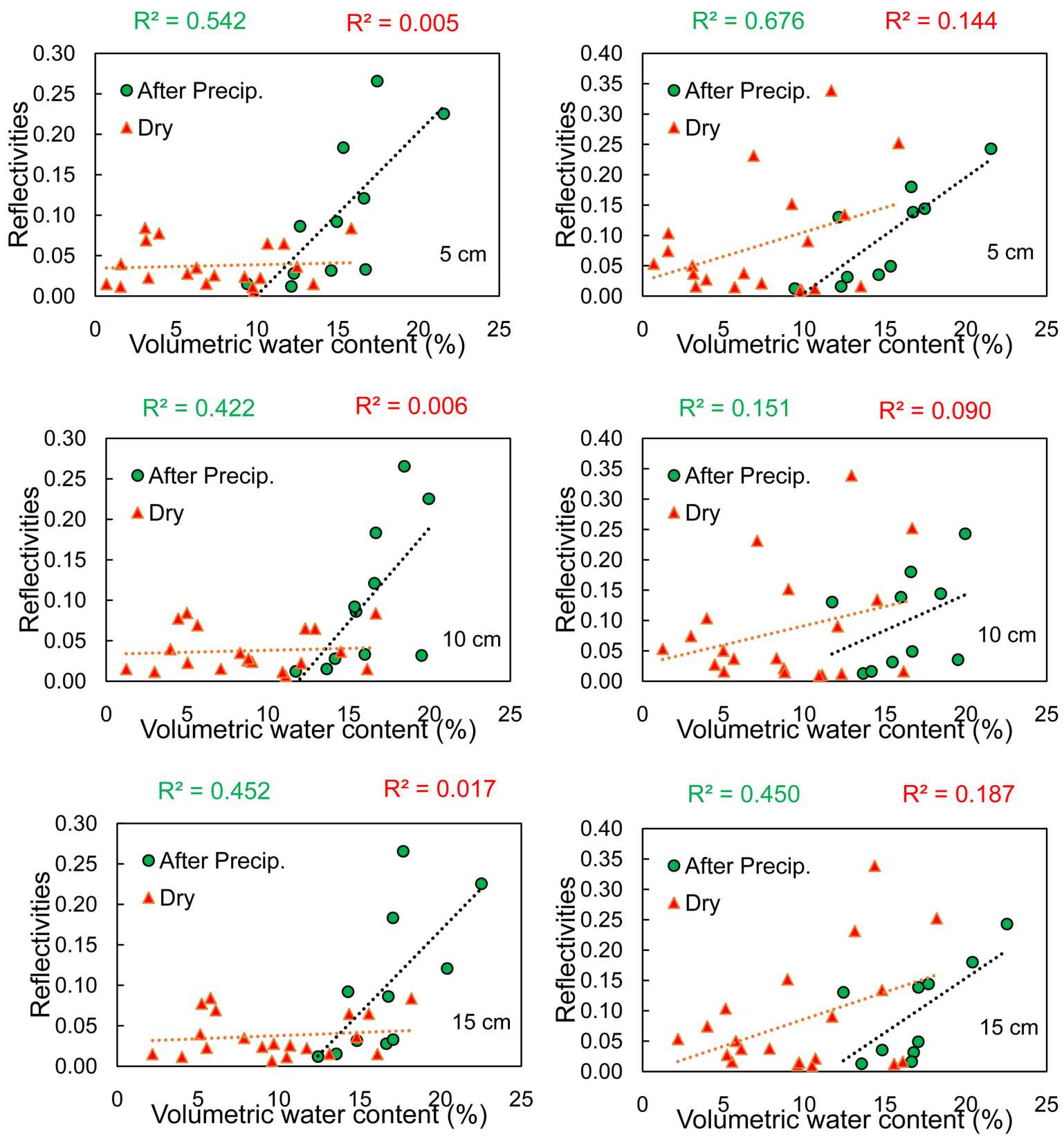

Figure 6. Correlations of reflectivity measured at $1.6 \mathrm{~m}$ (left panel) and $2.7 \mathrm{~m}$ (right panel) with volumetric water content of soil at $5 \mathrm{~cm}, 10 \mathrm{~cm}$, and $15 \mathrm{~cm}$ depths during 2014.

by the DMR software, which makes the signals almost parallel to plant stalks [15]. After adjustment, the relationship between adjusted reflectivity and VWC improved only for antenna height of $2.7 \mathrm{~m}$, especially for soil depths of 10 and $15 \mathrm{~cm}$ (Table 1). [13] also evaluated the effect of vegetation attenuation on GPS signal using equation from [18]. He concluded that, after attenuation caused by vegetation was accounted for, the mean error of the dielectric constant estimated from GPS reflectivity decreased, but the standard deviation increased.

\section{Conclusion}

This study was conducted to investigate the feasibility of using DMR to determine soil moisture content in cotton production fields and to evaluate the attenuation effect of vegetation (cotton) on reflected GPS signal. Results showed that DMR was able to detect soil moisture changes within one week after precipitation events that 


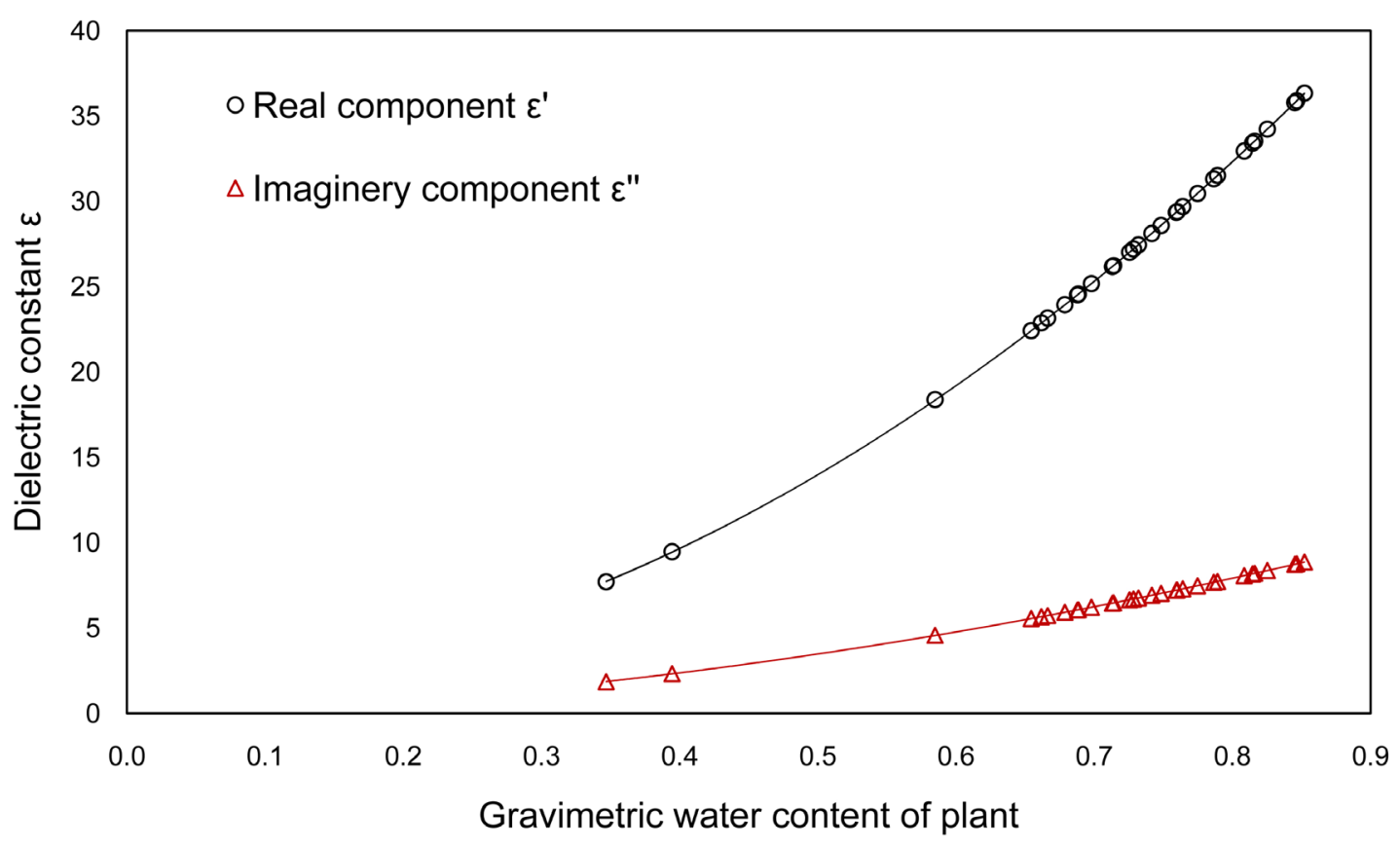

Figure 7. Relationship of dielectric constant with gravimetric moisture content of cotton leaves.

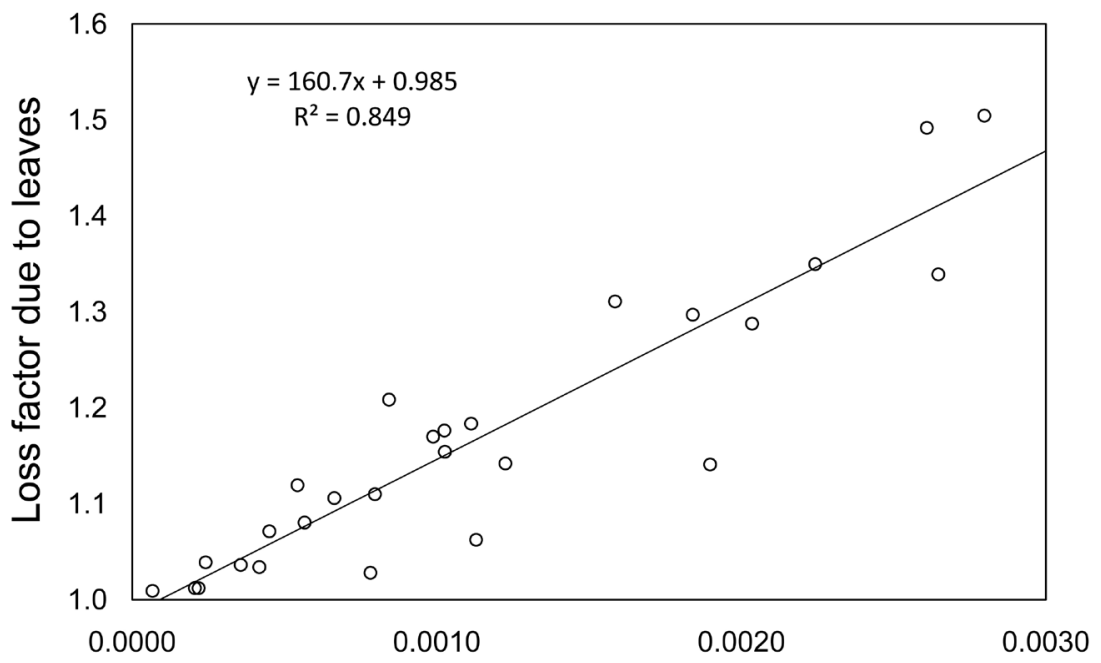

\section{Volumetric water content of plant}

Figure 8. Relationship of loss factor with volumetric water content of cotton.

were larger than $25 \mathrm{~mm}$ per day. However, the DMR readings were poorly correlated with soil volumetric water content during dry periods. The ability of this advanced remote sensing technology to differentiate between wet and dry soils has potential applications in large scale hydrological modeling and watershed management. The DMR was evaluated using a RF power divider and the result showed that the top and bottom channels of the system produced similar signal to noise ratio. In addition, calibration results over water showed a small variation in calibration factor $(1.14 \pm 0.06)$, which indicated that noise of the system was stable throughout the experiment. The dielectric constant of cotton, both real and imaginary components increased with gravimetric water content of cotton. In addition, the loss factor due to leaves increased with volumetric water content of cotton. However, attenuation effect of plant canopy was not significant. After applying loss factors to reflectivity, the correlations between reflectivity and actual soil moisture content improved only for measurements made for antenna height 
Table 1. Summary of coefficient of determination for reflectivity measurements with volumetric water content of soil.

\begin{tabular}{ccccccc}
\hline \multirow{2}{*}{ Year } & \multirow{2}{*}{ Height $^{\mathbf{1}}(\mathbf{m})$} & Depth $^{\mathbf{2}} \mathbf{( c m )}$ & \multicolumn{2}{c}{ Original Reflectivity } & \multicolumn{2}{c}{ Adjusted Reflectivity } \\
\cline { 4 - 7 } & & & After Precipitation & Dry & After Precipitation & Dry \\
\hline 2013 & 4.2 & 10 & 0.46 & 0.22 & $/$ & $/$ \\
2013 & 4.2 & 20 & 0.01 & 0.08 & $/$ & $/$ \\
2014 & 1.6 & 5 & 0.54 & 0.01 & 0.51 & 0.00 \\
2014 & 1.6 & 10 & 0.42 & 0.01 & 0.41 & 0.00 \\
2014 & 1.6 & 15 & 0.45 & 0.02 & 0.42 & 0.02 \\
2014 & 2.7 & 5 & 0.68 & 0.14 & 0.65 & 0.16 \\
2014 & 2.7 & 10 & 0.15 & 0.09 & 0.24 & 0.11 \\
2014 & 2.7 & 15 & 0.45 & 0.19 & 0.61 & 0.21 \\
\hline
\end{tabular}

${ }^{1}$ Height refers to distance of antenna platform to ground surface. ${ }^{2}$ Depth refers to distance of soil core samples took from ground surface.

of $2.7 \mathrm{~m}$. For irrigation purpose, the results suggested that the sensitivity of reflected GPS signals to soil moisture changes needed to be further studied before this technology could be utilized for irrigation scheduling in cotton production. Refinement of this technology will allow growers to install the DMR systems on top of an overhead irrigation system for site-specific and timely irrigation scheduling. This would eliminate the need to install moisture sensors in production fields, which usually can interfere with farming operations and increase production costs.

\section{Acknowledgements}

Technical Contribution No. 6433 of the Clemson University Experiment Station. This material is based upon work supported by NIFA/USDA, under project number SC-1700498. The authors acknowledge the support of the South Carolina Space Grant Consortium as well as technical support from NASA Langley Research Center, Hampton, VA, United States.

\section{Disclaimer}

Mention of a trade name does not imply endorsement of the product by Clemson University to the exclusion of others that might be available.

\section{References}

[1] Engman, E.T. and Chauhan, N. (1995) Status of Microwave Soil Moisture Measurements with Remote Sensing. Remote Sensing of Environment, 51, 189-198. http://dx.doi.org/10.1016/0034-4257(94)00074-W

[2] Hallikainen, M.T., Ulaby, F.T., Dobson, M.C., El-Rayes, M. and Wu, L.K. (1985) Microwave Dielectric Behavior of Wet Soil-Part 1: Empirical Models and Experimental Observations. IEEE Transactions on Geoscience and Remote Sensing, 1, 25-34. http://dx.doi.org/10.1109/TGRS.1985.289497

[3] Wang, J.R. and Schmugge, T.J. (1980) An Empirical Model for the Complex Dielectric Permittivity of Soils as a Function of Water Content. IEEE Transactions on Geoscience and Remote Sensing, 4, 288-295.

[4] Dobson, M.C., Ulaby, F.T., Hallikainen, M.T. and El-Rayes, M. (1985) Microwave Dielectric Behavior of Wet SoilPart II: Dielectric Mixing Models. IEEE Transactions on Geoscience and Remote Sensing, 1, 35-46. http://dx.doi.org/10.1109/TGRS.1985.289498

[5] Njoku, E.G. and Entekhabi, D. (1996) Passive Microwave Remote Sensing of Soil Moisture. Journal of Hydrology, 184, 101-129. http://dx.doi.org/10.1016/0022-1694(95)02970-2

[6] Jackson, T. and Schmugge, T. (1992) Surface Soil Moisture Measurement with Microwave Radiometry. Acta Astronautica, 35, 749-751.

[7] Entekhabi, D., Njoku, E.G., Neill, P.E., Kellogg, K.H., Crow, W.T., Edelstein, W.N., Entin, J.K., Goodman, S.D., Jackson, T.J., Johnson, J. and Kimball, J. (2010) The Soil Moisture Active Passive (SMAP) Mission. Proceedings of the IEEE, 98, 704-716. http://dx.doi.org/10.1109/JPROC.2010.2043918

[8] Schwank, M., Mätzler, C., Guglielmetti, M. and Flühler, H. (2005) L-Band Radiometer Measurements of Soil Water under Growing Clover Grass. IEEE Transactions on Geoscience and Remote Sensing, 43, 2225-2237. 
http://dx.doi.org/10.1109/TGRS.2005.855135

[9] Jackson, T.J., Le Vine, D.M., Swift, C.T., Schmugge, T.J. and Schiebe, F.R. (1995) Large Area Mapping of Soil Moisture Using the ESTAR Passive Microwave Radiometer in Washita'92. Remote Sensing of Environment, 54, $27-37$. http://dx.doi.org/10.1016/0034-4257(95)00084-E

[10] Kerr, Y.H., Waldteufel, P., Wigneron, J., Martinuzzi, J., Font, J. and Berger, M. (2001) Soil Moisture Retrieval from Space: The Soil Moisture and Ocean Salinity (SMOS) Mission. IEEE Transactions on Geoscience and Remote Sensing, 39, 1729-1735. http://dx.doi.org/10.1109/36.942551

[11] Larson, K.M., Small, E.E., Gutmann, E.D., Bilich, A.L., Braun, J.J. and rotny, V.U. (2008) Use of GPS Receivers as a Soil Moisture Network for Water Cycle Studies. Geophysical Research Letters, 35. http://dx.doi.org/10.1029/2008GL036013

[12] Katzberg, S.J., Torres, O., Grant, M.S. and Masters, D. (2006) Utilizing Calibrated GPS Reflected Signals to Estimate Soil Reflectivity and Dielectric Constant: Results from SMEX02. Remote Sensing of Environment, 100, 17-28. http://dx.doi.org/10.1016/j.rse.2005.09.015

[13] Masters, D., Axelrad, P. and Katzberg, S. (2004) Initial Results of Land-Reflected GPS Bi-Static Radar Measurements in SMEX02. Remote Sensing of Environment, 92.4, 507-520. http://dx.doi.org/10.1016/j.rse.2004.05.016

[14] Privette, C.V., Khalilian, A., Torres, O. and Katzberg, S. (2011) Utilizing Space-Based GPS Technology to Determine Hydrological Properties of Soils. Remote Sensing of Environment, 115, 3582-3586. http://dx.doi.org/10.1016/j.rse.2011.08.019

[15] Grant, M.S. (2006) Surface Reflected Global Positioning System Signals for Terrain Classification (Order No. 3225963). Available from ProQuest Dissertations \& Theses Global (304966360). http://search.proquest.com.libproxy.clemson.edu/docview/304966360?accountid=6167

[16] Privette III, C.V., Khalilian, A., Bridges, W., Katzberg, S., Torres, O., Han, Y.J., Maja, J.M. and Qiao, X. (2016) Relationship of Soil Moisture and Reflected GPS Signal Strength. Advances in Remote Sensing, 5, 18. http://dx.doi.org/10.4236/ars.2016.51002

[17] ASABE Standards. 2012. D245.6. Moisture Relationships of Plant-based Agricultural Products. ASABE St. Joseph, Mich.

[18] Ulaby, F.T., Moore, R.K. and Fung, A.K. (1986) Microwave Remote Sensing Active and Passive-Volume III: From Theory to Applications. Artech House, Norwood.

[19] Ulaby, F.T. and El-Rayes, M. (1987) Microwave Dielectric Spectrum of Vegetation-Part II: Dual-Dispersion Model. IEEE Transactions on Geoscience and Remote Sensing, 5, 550-557. http://dx.doi.org/10.1109/TGRS.1987.289833

\section{Submit or recommend next manuscript to SCIRP and we will provide best service for you:}

Accepting pre-submission inquiries through Email, Facebook, Linkedin, Twitter, etc

A wide selection of journals (inclusive of 9 subjects, more than 200 journals)

Providing a 24-hour high-quality service

User-friendly online submission system

Fair and swift peer-review system

Efficient typesetting and proofreading procedure

Display of the result of downloads and visits, as well as the number of cited articles

Maximum dissemination of your research work

Submit your manuscript at: http://papersubmission.scirp.org/ 